\title{
Health Risk Assessment of Dermal Exposure to Chlorpyrifos among Applicators on Rice Farms in Ghana
}

\begin{abstract}
Albert Atabila ${ }^{a}$, Dung Tri Phung ${ }^{a}$, Jonathan N. Hogarh ${ }^{b}$, Ross Sadler ${ }^{a}$, Des Connell ${ }^{\mathrm{a}}$, and
\end{abstract} Cordia $\mathrm{Chu}^{\mathrm{a}}$

${ }^{a}$ Centre for Environment and Population Health, Griffith School of Environment, Griffith University, 170 Kessel Road, Nathan, QLD 4111, Australia.

${ }^{b}$ Department of Environmental Science, College of Science, Kwame Nkrumah University of Science and Technology, Kumasi, Ghana.

Abstract

Generally, there is limited information on pesticide absorbed dose levels and health risk attributable to the dermal route of exposure among applicators. The objective of this study was to evaluate the absorbed dose levels and consequent health risk from dermal exposure to chlorpyrifos among applicators on rice farms in Ghana. The whole-body dosimetry technique was used to capture chlorpyrifos residues penetrating the applicators' clothing and reaching their skin, as well as residues reaching uncovered body areas of the applicators. Acute $\left(\mathrm{ADD}_{\mathrm{D}}\right)$ and chronic $\left(\mathrm{LADD}_{\mathrm{D}}\right)$ absorbed dose levels of chlorpyrifos were estimated from the residues and plotted as cumulative probability distributions. Health risk from chlorpyrifos exposure was characterized using the hazard quotient technique. Three of the four acute exposure guideline values used in the study indicated that applicators, represented by the median-exposed $\left(\mathrm{ADD}_{\mathrm{D}}\right.$, $15 \mu \mathrm{g} / \mathrm{kg} /$ day $)$ and the $5 \%$ - highly exposed (ADD, $27 \mu \mathrm{g} / \mathrm{kg} /$ day) groups were at high risk of acute adverse health effects due to chlorpyrifos exposure, with hazard quotient values ranging from 1.5 to 5 and 2.7 to 9 , respectively. Regarding chronic adverse health effects, none of the guideline values suggested risk among the median-exposed group ( $\mathrm{LADD}_{\mathrm{D}}, 0.3 \mu \mathrm{g} / \mathrm{kg} / \mathrm{day}$ ), with $\mathrm{HQ}_{50}$ values ranging from 0.03 to 1 . However, two of the chronic exposure guideline 
values suggested that the $5 \%$ - highly exposed group ( $\mathrm{LADD}_{\mathrm{D}}, 0.6 \mu \mathrm{g} / \mathrm{kg} /$ day) may be adversely affected, with $\mathrm{HQ}_{95}$ values ranging from 1.2 to 2 . These findings highlight the importance of the dermal route as a major pesticide exposure pathway and suggest possible exposure minimization strategies.

Keywords: risk assessment, dermal exposure, chlorpyrifos, pesticide applicators, wholebody dosimetry

\subsection{Introduction}

Chlorpyrifos is an organophosphate insecticide which is moderately toxic to humans (WHO, 2010) and commonly applied by farmers around the world to protect crops (Eaton et al., 2008; Grube et al., 2011; John and Shaike, 2015). In exposed individuals, the oxon form of chlorpyrifos reacts with and inhibits the enzyme, acetylcholinesterase, which is responsible for hydrolysing the neurotransmitter, acetylcholine. The inhibition of acetylcholinesterase leads to the build-up of excess acetylcholine at their sites of action, which in turn result in overstimulation of the cholinergic nerve terminals. Ultimately, the normal functioning of the nervous systems can be hampered (Costa, 2006; Yang and Deng, 2007; Eaton et al., 2008), resulting in acute health effects including tremor, paralysis, confusion, convulsion, coma, gastro-intestinal distress and death (Colombo et al., 2005; Costa, 2006; Yang and Deng, 2007). Exposure to the insecticide may also lead to chronic health effects such as developmental and neurobehavioral anomalies (Whyatt et al., 2004; Rauh et al., 2012). 
49 Generally, exposure to pesticides occurs mainly through the dermal, inhalation and oral routes.

However, with agricultural applicators, the dermal route is usually the most prominent exposure route (Dowling and Seiber, 2002; Damalas and Eleftherohorinos, 2011; Fenske et al., 2012; Cao et al., 2015). This is particularly true in tropical countries, where hot and humid weather conditions discourage applicators from using adequate Personal Protective Equipment (PPE); and the means of application is mainly by back-pack spray devices. With chlorpyrifos, the dermal route has been reported to account for about $94-96 \%$ of the total exposure among applicators (Fenske et al., 2012). Owing to the importance of the dermal route, a considerable number of studies have been conducted to assess dermal exposure to chlorpyrifos among applicators in tropical countries (Farahat et al., 2010; Pan and Siriwong, 2010; Fenske et al., 2012; Atabila et al., 2017). Although, these studies have increased knowledge on the levels and patterns of chlorpyrifos exposure pertaining to the dermal route among applicators, there is limited information on the absorbed dose levels and health risk attributable to this route of exposure.

Techniques for assessing dermal pesticide exposure include the whole-body dosimetry, patches, chemical removal and fluorescent tracer techniques (Durham and Wolfe, 1962; Chester, 1993; Fenske, 1993). The whole-body dosimetry technique has been considered as the most accurate for evaluating dermal pesticide exposure among applicators, because it does not involve extrapolation of exposure from one anatomical area to another (Fenske, 1993; 1997). We have previously reported on the use of the whole-body dermal dosimetry technique to evaluate the magnitude, patterns and determinants of dermal exposure to chlorpyrifos among applicators on rice farms in Ghana (Atabila et al., 2017). Ghana was selected for the study because it is a tropical developing country with limited use of PPE (Ntow et al., 2006; Mattah et al., 2015) and significant level of chlorpyrifos application by farmers (Darko and Akoto, 
2008; Ntow et al., 2008; Botwe et al., 2012; 2016; Fosu-Mensah et al., 2016). The objective of the present study was to estimate absorbed doses of chlorpyrifos and characterize the associated health risk among the applicators, using data obtained from our previous study (Atabila et al., 2017).

\subsection{Methods}

\subsection{Data Collection and Laboratory Analysis for Chlorpyrifos}

The details of the data collection and laboratory analysis procedures, which were approved by the Ghana Health Service Ethical Review Committee (GHS-ERC: 10/07/15) and Griffith University Human Ethics Committee (GU Ref. No: ENV/24/15/HREC), have previously been described (Atabila et al., 2017). Briefly, the study involved a cross-section of applicators (n= 24) from a typical farming community in the southern part of Ghana. In this area, rice is grown under small scale conditions with irrigation and chlorpyrifos is commonly applied to control insect pests. The data collection procedures were based on the protocols of the World Health Organisation (WHO, 1982) and the Organisation for Economic Co-operation and Development (OECD, 1997) .

Sampling for each applicator was done when rice crops were being sprayed with chlorpyrifos (Dursban - 480g/L Emulsifiable Concentrate, EC) from hand-pressurized back-pack spraying devices. On the day of spraying, the applicators were initially dressed in a new set of sampling media that consisted of Tyvek under-wear garment, white cotton hand gloves and socks. The applicators then wore their usual farm clothes over the sampling media, before commencing any pesticide spraying activity. The sampling media were intended to capture chlorpyrifos residues penetrating the applicators' clothing and reaching their skin, as well as residues 
reaching body areas of the applicators not covered by their farm clothing. Immediately after the spraying activities, the sampling media were carefully removed from the applicators, folded, wrapped with aluminium foil, placed in pre-labelled zip-lock plastic bags, packed in an ice chest with ice, transported to the laboratory and stored at $-25^{\circ} \mathrm{C}$ until analysed.

The extraction and analysis of the sampling media for chlorpyrifos were carried out based on a modified version of the analytical methods for agricultural chemicals published by Japan Department of Food Safety (DFS, 2006). Extracts from the sampling media were analysed using a Varian CP 3800 Gas Chromatograph (Varian Associates Inc, USA) equipped with Pulsed Flame Photometric Detector (PFPD) and a CombiPAL auto sampler.

\subsection{Selection of Chlorpyrifos Dermal Absorption Factor (DAF) for Calculating Absorbed Dose from Dermal Exposure}

Dermal Absorption Factor (DAF) provides a measure of the proportion of pesticides absorbed through the skin into the body of exposed individuals. Consequently, DAFs have been established for pesticides for purposes of exposure and health risk assessment. These DAFs have been determined mainly through experimental in vivo, in vitro as well as Quantitative Structure-Activity Relationship (QSAR) studies (Ngo et al., 2010). However, results from in vivo studies are more acceptable because they are believed to give more accurate outcomes since they are based on direct measurement (Zendzian, 1994; Mueller et al., 2008).

In in vivo pesticide dermal absorption studies, a certain quantity of the pesticide is applied over a defined area of the skin of study subjects. The quantities of the metabolite or the parent 
compound of the applied pesticide is then measured in body fluids such as the urine and blood, after a specified period of time. The quantity recovered is used to estimate the absorbed dose and then expressed as a percentage of the original dose applied on the skin, to obtain the DAF. Thus, DAF may be mathematically expressed as:

The DAF proposed for chlorpyrifos by different authors, ranges from 1 to $9.6 \%$ (Nolan et al., 1984; Thongsinthusak, 1991; Griffin et al., 1999; Geer et al., 2004; Meuling et al., 2005). The variation in the DAF values could be due to variations in the experimental parameters, which are discussed below. To determine the most appropriate DAF to apply in the current study, the following criteria were used to identify studies from the scientific literature that have evaluated DAF for chlorpyrifos: primary study; published in scientific peer reviewed journal; used acceptable experimental technique; and conducted with human subjects.

The parameters of the studies identified are summarized in Table 1. A major difference in the experimental parameters among the studies is the levels of chlorpyrifos applied to the skin. The exposure levels in the studies by Nolan et al. (1984) and Griffin et al. (1999) are problematic. This is mainly because, the levels $\left(4,160 \mu \mathrm{g} / \mathrm{cm}^{2}\right.$ and $367 \mu \mathrm{g} / \mathrm{cm}^{2}$, respectively) are much higher than the levels found in field conditions, which range from 1 to $25 \mu \mathrm{g} / \mathrm{cm}^{2}$ (Thongsinthusak et al., 1999; Meuling et al., 2005). As with many other compounds, the percentage of absorbed dose of chlorpyrifos is inversely proportional to the applied exposure level, when the limit of the absorptive capacity of the skin is reached (Thongsinthusak et al., 1999; Meuling et al., 2005; Mueller et al., 2008; Ngo et al., 2010). The DAF of the studies by 
147 Nolan et al. (1984) and Griffin et al. (1999) may have therefore, under-estimated the skin 148 absorption rate for chlorpyrifos. Another major difference in the parameters used in the DAF

149 experiments is the duration of exposure, which ranged from 4 to 20 hours. The duration of the experiments by Griffin et al. (1999) and Meuling et al. (2005), which were 8 and 4 hours, respectively, are typical of those found in field conditions. However, the exposure duration of the experiment by Nolan et al. (1984), which was 12 to 20 hours, can be more than what apply in typical field conditions.

With the present study, the DAF proposed by Meuling et al. (2005) was regarded more appropriate considering the applied dose $\left(50 \mu \mathrm{g} / \mathrm{cm}^{2}\right)$ and duration (4 hours) of the experiment, which were closer to the spraying characteristics of the present study (applied dose of 0.3 to 13 $\mu \mathrm{g} / \mathrm{cm}^{2}$ and spray duration of 0.4 to 1.8 hours) (Atabila et al., 2017).

\subsection{Calculation of Absorbed Daily Dose $\left(\mathrm{ADD}_{\mathrm{D}}\right)$ and Lifetime Average Daily Dose $\left(\mathrm{LADD}_{\mathrm{D}}\right)$ of Chlorpyrifos from Dermal Exposure}

Total Dermal Exposure (TDE) for each applicator was obtained as the total mass of chlorpyrifos residues extracted from all the sampling media for each applicator. Using the TDE data, Absorbed Daily Dose $\left(\mathrm{ADD}_{\mathrm{D}}\right)$ of chlorpyrifos from dermal exposure was estimated with the following equation, adapted from Health Canada (2014): 
169

170

171

173

174

175

176

177

178

179

180

181

182

183

184

185

186

187

188

189

190

where, $\mathrm{ADD}_{\mathrm{D}}$ is the dermal Absorbed Daily Dose ( $\mu \mathrm{g} / \mathrm{kg} /$ day); TDE, Total Dermal Exposure ( $\mu \mathrm{g} /$ day); DAF, Dermal Absorption Factor (4.3 \%) (Meuling et al., 2005); and BW, Body Weight of each applicator $(\mathrm{kg})$.

Lifetime Average Daily Dose $\left(\mathrm{LADD}_{\mathrm{D}}\right)$ of chlorpyrifos from dermal exposure with the applicators was estimated with the following equation, adapted from and USEPA and Health Canada_(USEPA, 2007; Health Canada, 2014):

$$
\mathrm{LADD}_{\mathrm{D}}=\left(\mathrm{ADD}_{\mathrm{D}} \times \mathrm{EF} \times \mathrm{ED}\right) / \mathrm{AT}
$$

Equation 3

where, $\mathrm{ADD}_{\mathrm{D}}(\mu \mathrm{g} / \mathrm{kg} / \mathrm{day})$ is the dermal Absorbed Daily Dose of chlorpyrifos of the applicator; EF, the Exposure Frequency (Number of days per year); ED, the Exposure Duration (Work lifetime years); and AT, the Averaging Time [(life expectancy in years - application start age in years) x 365 days/ year].

\subsection{Risk Characterization}

The Cumulative Probabilities (CPs) of the estimated $\mathrm{ADD}_{\mathrm{D}}$ and $\mathrm{LADD}_{\mathrm{D}}$ values were calculated using the equation below, after ranking the data points from the lowest to the highest:

$$
\mathrm{CP}(\%)=(\mathrm{i} / \mathrm{n}+1) \times 100
$$

Equation 4

where, $\mathrm{CP}$ is cumulative probability $(\%), \mathrm{i}$, the $\mathrm{i}^{\text {th }}$ point and $\mathrm{n}$, the total number of data points. 
192 Using the $\mathrm{ADD}_{\mathrm{D}}$ and $\mathrm{LADD}_{\mathrm{D}}$ values together with the $\mathrm{CP}$ values, Cumulative Probability 193 Distribution (CPD) plots were constructed. The risk of adverse health effect was characterized 194 as a ratio of the exposure dose at the $50^{\text {th }}\left(\mathrm{HQ}_{50}\right)$ and $95^{\text {th }}\left(\mathrm{HQ}_{95}\right)$ percentiles to chlorpyrifos guideline values. The acute and chronic guideline values set by the WHO, USEPA, APVMA and Phung et al. (2015) were used in this study. HQ values less or equal to unity are generally believed to be associated with a low probability for the occurrence of adverse health effects, whereas HQ values more than unity may be associated with higher probability for the occurrence of adverse health effects.

\section{Results and Discussion}

\subsection{Total Dermal Exposure (TDE) and Absorbed Daily Dose (ADD $)$ of Chlorpyrifos}

The TDE, $\mathrm{ADD}_{\mathrm{D}}$ and $\mathrm{LADD}_{\mathrm{D}}$ values estimated are presented in Table 2. The $\mathrm{ADD}_{\mathrm{D}}$ of chlorpyrifos with the applicators ranged from 5 to $29 \mu \mathrm{g} / \mathrm{kg} /$ day, with a mean of $16 \mu \mathrm{g} / \mathrm{kg} / \mathrm{day}$ ( \pm 6.0 ). The mean acute exposure dose of the present study is about 7 times less than that of a similar dermal exposure assessment study conducted with applicators on rice farms in Thailand. In that study, a mean acute dose of $105.8 \mu \mathrm{g} / \mathrm{kg} /$ day was found with male applicators. Slightly high levels (mean of $119 \mu \mathrm{g} / \mathrm{kg} /$ day) were found with female applicators (Lappharat et al., 2014). The authors explained that the higher body weight of the males $(60.9 \mathrm{~kg})$ compared to that of the female $(54.1 \mathrm{~kg})$ accounted for the relatively lesser dose of chlorpyrifos with the males. Usually, for a given pesticide concentration, the estimated dose is inversely related to the body weight of applicators. In addition, the average size of rice farms in Thailand is about 2.5 hectares (ha) (Pornpratansombat et al., 2011), while that in the present study was about 0.5 ha (Atabila et al., 2017). The Thai applicators were therefore more likely to use larger quantities 
217

218

219

220

221

222

223

224

225

226

227

228

229

230

231

232

233

234

235

236

237

238

of the insecticide than the Ghanaian applicators, resulting in the higher exposure levels reported in the Thai study.

The difference in the exposure dose between the Thai and Ghanaian applicators may also result partly from the different dermal exposure measurement approaches used in the two studies. Whereas the whole-body dosimetry approach was used in the present study, the patch method was used in the Thai study. A major limitation of the patch method is the tendency to incorrectly estimate exposure levels because the exposure estimate involves extrapolation from one body area to another. Pesticide depositions on different body areas are usually not uniform and therefore makes extrapolation of exposure problematic (Schneider et al., 2000; Frenich et al., 2002; Behroozy, 2013).

\subsection{Lifetime Average Daily Dose (LADD $)$ of Chlorpyrifos from Dermal Exposure}

$\mathrm{LADD}_{\mathrm{D}}$ measured the daily chlorpyrifos exposure during spray events over the working life of the applicators (i.e. chronic exposure). Chronic exposure to pesticides have been associated with adverse health effects on neurological and behavioural functions, such as psychomotor, verbal memory and coordination skills (Jamal et al., 2002; Munoz-Quezada et al., 2016). More debilitating chronic effects include Parkinson's disease Alzheimer's disease and various cancers (Bassil et al., 2007; Dhillon et al., 2008; Yan et al., 2016). Despite the importance of chronic exposure, the majority of the studies that evaluated pesticides exposure among agricultural applicators focused on acute exposure (Ngo et al., 2010). 
240

241

242

243

244

245

246

247

248

249

250

251

252

253

254

255

256

257

258

259

260

261

262

263

However, chronic exposure to pesticides can be obtained by extrapolation based on acute exposure measurements (Ngo et al., 2010; Phung et al., 2012). Assuming the current pattern of pesticide use with the applicators in this study will be similar to future use patterns, chronic exposure dose for each applicator was estimated based on a single acute exposure dose, averaged over the expected life time (Equation 3). The estimated chronic exposure dose $\left(\mathrm{LADD}_{\mathrm{D}}\right)$ found with the applicators ranged from 0.1 to $0.5 \mu \mathrm{g} / \mathrm{kg} / \mathrm{day}$, with a mean of $0.3 \mu \mathrm{g} / \mathrm{kg} /$ day (Table 2). No comparable study evaluating chronic exposure to chlorpyrifos based on dermal assessment was identified in the scientific literature.

\subsection{Cumulative Probability Distribution Plots of $\mathrm{ADD}_{\mathrm{D}}$ and $\mathrm{LADD}_{\mathrm{D}}$ of Chlorpyrifos with the Applicators from Dermal Exposure}

The CPD plots of $\mathrm{ADD}_{\mathrm{D}}$ and $\mathrm{LADD}_{\mathrm{D}}$ data in Table 2 are presented in Figures 1 and 2, respectively. The CPD plots provide the relative frequencies of all chlorpyrifos exposure doses with the applicators, allowing the determination of the probability of occurrence of the doses. The dose corresponding to the $50^{\text {th }}\left(\mathrm{CP}_{50}\right)$ and $95^{\text {th }}\left(\mathrm{CP}_{95}\right)$ Cumulative Probability of chlorpyrifos $\mathrm{ADD}_{\mathrm{D}}$ were found to be $15 \mu \mathrm{g} / \mathrm{kg} /$ day and $27 \mu \mathrm{g} / \mathrm{kg} /$ day, respectively. With $\mathrm{LADD}_{\mathrm{D}}$ of Chlorpyrifos, the dose corresponding to $\mathrm{CP}_{50}$ and $\mathrm{CP}_{95}$ were determined to be 0.3 $\mu \mathrm{g} / \mathrm{kg} /$ day and $0.6 \mu \mathrm{g} / \mathrm{kg} /$ day, respectively. The linear part of the plots for both $\mathrm{ADD}_{\mathrm{D}}$ and $\mathrm{LADD}_{\mathrm{D}}$ were all determined to lie between $8 \%$ and $92 \%$ of the CPD, based on the $\mathrm{R}^{2}$ values. The corresponding equations of the linear regression lines fitted to the CPD plot of $\mathrm{ADD}_{\mathrm{D}}$ and $\mathrm{LADD}_{\mathrm{D}}$, respectively were: 


\subsection{The Hazard Quotient Technique}

267 Conventionally, the Hazard Quotient (HQ) for non-carcinogenic toxicants is obtained by identifying a single point estimate of exposure that is most representative of a population and dividing it by an appropriate guideline value of the toxicant (USEPA, 1992). HQ values less than or equal to unity imply minimal or no risk of adverse health effects, whereas, HQ values above unity constitute risks of adverse health effects due to exposure to the toxicant.

The HQ technique for characterising health risks of environmental and occupational toxicants is simple to calculate and to understand. The technique, however, cannot usually account for the variability of exposure and sensitivity among a population. A strategy to partly address this weakness is to calculate HQ at various percentiles of exposure (Cao et al., 2010; Phung et al., 2012; Marasinghe et al., 2014; Edokpolo et al., 2015; Sadler et al., 2016). In this study, HQ was calculated for exposures at $\mathrm{CP}_{50}\left(\mathrm{HQ}_{50}\right)$ and $\mathrm{CP}_{95}\left(\mathrm{HQ}_{95}\right)$, which represents the risk among the median-exposed group and the 5\% highly-exposed group, respectively. The risk levels among these two groups are regarded the most important in terms of managing toxicant exposure and adverse health effects in a population. This is because, the exposure level and risk among the median-exposed group is the most representative of the whole population; and interventions aimed to reduce exposure and risk levels among the 5\% highly-exposed group to safe levels, will provide protection to the majority of the target population. 


\subsection{Hazard Quotients (HQs) Values from Absorbed Daily Dose (ADD $\left.{ }_{D}\right)$ of Chlorpyrifos}

289

The Hazard Quotient (HQ) technique was applied using different guideline values to quantitatively describe the risk of adverse health effects due to chlorpyrifos exposure with the applicators studied. The HQ values corresponding to $\mathrm{CP}_{50}\left(\mathrm{HQ}_{50}\right)$ and $\mathrm{CP}_{95}\left(\mathrm{HQ}_{95}\right)$ for $\mathrm{ADD}_{\mathrm{D}}$ are presented in Table 3. The $\mathrm{HQ}_{50}$ values for $\operatorname{ADD}_{\mathrm{D}}(3,1.5$, and 5) obtained with the guideline values derived by the USEPA, APVMA, and Phung et al. (2015), respectively, were above unity. But $\mathrm{HQ}_{50}$ was less than unity with the guideline value set by the $\mathrm{WHO}\left(\mathrm{HQ}_{50}=0.2\right)$. Similarly, $\mathrm{HQ}_{95}$ for $\mathrm{ADD}_{\mathrm{D}}$ obtained with the guideline value by USEPA, APVMA and Phung et al. (2015) were all above unity $\left(\mathrm{HQ}_{95}=5.4,2.7\right.$, and 9 respectively). However, $\mathrm{HQ}_{95}$ with the WHO's guideline value was less than unity $\left(\mathrm{HQ}_{95}=0.3\right)$. The $\mathrm{HQ}_{50}$ values obtained for $\mathrm{ADD}_{\mathrm{D}}$ with the guideline values set by the USEPA, APVMA, and Phung et al. (2015) suggest that there was a high chance for occurrence of adverse health effects due to acute chlorpyrifos exposure, both with the median exposed group as well as the $5 \%$ highly-exposed group of the applicators studied $\left(\mathrm{HQ}_{50}\right.$ and $\left.\mathrm{HQ}_{95}>1\right)$. On the contrary, the $\mathrm{HQ}$ values calculated with the WHO's guideline value indicate that there was low chance for adverse health effects to occur due to acute chlorpyrifos exposure with both the median exposed group and the $5 \%$ highlyexposed group $\left(\mathrm{HQ}_{50}\right.$ and $\left.\mathrm{HQ}_{95}<1\right)$.

A dose-response evaluation with chlorpyrifos conducted by Phung et al. (2015) (Phung et al., 2015), using human epidemiological studies, suggests that the acute adverse health effects that could occur with the median exposed and 5\% highly-exposed groups, may include Acetylcholinesterase (AChE) and Butyrylcholinesterase (BuChE) inhibition; sensory and motor effects; and subclinical neuropathy. 


\subsection{Hazard Quotients (HQs) Values from Lifetime Average Daily Dose (LADD $)$ of Chlorpyrifos}

The $\mathrm{HQ}_{50}$ and $\mathrm{HQ}_{95}$ values for $\mathrm{LADD}_{\mathrm{D}}$ are presented in Table 4. The $\mathrm{HQ}_{50}$ values obtained using the guideline values set by the WHO, USEPA, APVMA, and Phung et al. (2015) were all less than or equal to unity $\left(\mathrm{HQ}_{50}=0.03,1.0,0.1\right.$, and 0.6 , respectively). Likewise, the $\mathrm{HQ}_{95}$ values obtained with the guideline values of the WHO and APVMA were less than unity $\left(\mathrm{HQ}_{95}\right.$ $=0.1$ and 0.2, respectively). However, the $\mathrm{HQ}_{95}$ calculated with USEPA's and Phung et al. (2015)'s guideline values were more than unity $\left(\mathrm{HQ}_{95}=2.0\right.$ and 1.2, respectively).

With the $\mathrm{HQ}_{50}$ values obtained for $\mathrm{LADD}_{\mathrm{D}}$, all the guideline values suggest that there was low chance for adverse health effects to occur due to chronic exposure to chlorpyrifos with the median exposed group of the applicators studied $\left(\mathrm{HQ}_{50}<1\right)$. Similarly, the guideline values from the WHO and APVMA suggest a low chance of adverse health effects among the highlyexposed group, regarding chronic exposure to chlorpyrifos $\left(\mathrm{HQ}_{95}<1\right)$. In contrast, the guideline values by the USEPA and Phung et al. (2015) suggest a high chance for chronic adverse health effects among the highly-exposed group due to chronic chlorpyrifos exposure $\left(\mathrm{HQ}_{95}>1\right)$. A review of a set of single human epidemiological studies conducted by Phung et al. (2015) showed that - possible chronic adverse health effects that may be experienced by the $5 \%$ highly-exposed group $\left(\mathrm{CP}_{95}\right)$ of the applicators due to chronic exposure to chlorpyrifos include DNA damage in sperm, decreased testosterone and thyroid hormone free $\mathrm{T}_{4}$ levels; and increased Thyroid Stimulating Hormones (TSH) Strategies that the applicators may adopt to reduce the levels of chlorpyrifos exposure and consequent health risk include wearing appropriate PPE such as coveralls (Tsakirakis et al., 2011; Koureas et al., 2014) and hand gloves (Bradman et al., 2009; Furlong et al., 2015). 


\subsection{Variations Resulting from Different Guideline Values}

338

The variations in both the acute and chronic exposure guideline values for chlorpyrifos have resulted in different $\mathrm{HQ}$ values for both $\mathrm{CP}_{50}$ and $\mathrm{CP}_{95}$ (Tables 2 and 3). The differences in the guideline values are a result of the different approaches and toxicological endpoints that were applied to derive the values. The guideline values set by the WHO, USEPA, and APVMA were all based on the No Observable Adverse Effect Level (NOAEL) approach. In this approach, experiments were conducted with appropriate animal models to identify toxicological endpoints and the endpoint with the lowest NOAEL was selected and relevant safety factors applied to derive the guideline values (Connell, 2005). The guideline values derived by Phung et al. (2015) on the other hand, were based on evaluation using data from human epidemiological studies. It is suggested that these guidelines are more directly applicable to humans without the need for safety factors, which is subjective and can introduce uncertainties in the risk characterization process (Wu et al., 2008).

Countries that do not have their own national guideline values, such as Ghana, usually rely on the guideline values derived by international and other organisations, for health risk assessment studies. Therefore, the wide variation in the guideline values of toxicants, such as chlorpyrifos, complicates health risk assessment efforts in such countries. Consequently, a burden is placed on the authorities responsible for human health risk assessment in those countries to decide on the most appropriate guideline value that is suitable to their context. To select a suitable guideline value, consideration may be given to guideline values that would provide the maximum level of protection to the general population. It should also be practical so that facilities and personnel are available to enforce the guideline selected. Guideline values that are relatively lower may be regarded as the most protective of public health. 
361

362

363

364

365

366

367

368

369

370

371

372

373

374

375

376

377

378

379

380

381

382

383

384

\subsection{Conclusions}

The present study is the first to employ the whole-body dosimetry technique to provide data on the absorbed dose of chlorpyrifos and the consequent health risk relating to the dermal exposure route, in a tropical environment. Three of the four acute exposure guideline values used in the study indicated that most of the applicators, represented by the median exposed group were at high risk of acute adverse health effects due to chlorpyrifos exposure, with hazard quotient $\left(\mathrm{HQ}_{50}\right)$ values ranging from 1.5 to 5 . In addition, the 5\% highly - exposed group, with hazard quotient $\left(\mathrm{HQ}_{95}\right)$ values of 2.7 to 9 were at much higher risk of acute adverse health effects. Regarding chronic adverse health effects, none of the guideline values suggested risk among the median-exposed group, with $\mathrm{HQ}_{50}$ values ranging from 0.03 to 1 . However, two of the four chronic exposure guideline values suggested that the 5\%- highly exposed group may be adversely affected due to chronic chlorpyrifos exposure, with $\mathrm{HQ}_{95}$ values ranging from 1.2 to 2. These findings highlight the importance of the dermal route as a major pathway of exposure and suggest possible exposure minimization strategies.

\section{Conflict of Interest}

None

\section{Acknowledgements}

This study was supported with funding from Griffith University (Griffith University International Postgraduate Research Scholarship and Griffith University Postgraduate Research Scholarship) and Griffith School of Environment (PhD fieldwork fund). Special thanks go to the rice farmers of Asutsuare and Akuse (Ghana) as well as the staff of Kpong 
Irrigation Scheme (Asutsuare, Ghana), particularly Albert F. Swatson, Raphael Edifor, Samuel Kwakye and Moses Kodjotse, for their tremendous support during the field work. The authors are also grateful to Mrs. Benedicta Adewuti, Martin Amega-Yevu, and Ishmael Sumaila Narteh of Osukoku Health Centre (Asutsuare) for their assistance during the fieldwork. In addition, appreciation goes to the Management and Staff of the Pesticide Residues Laboratory of Ghana Standards Authority, especially, Mr. Clifford Frimpong, Dr. Paul Osei-Fosu and Mr. Duke Henry N. A. Ashie, for their support during the laboratory analytical work.

\section{References}

Atabila, A., Phung, D. T., Hogarh, J. N., Osei-Fosu, P., Sadler, R., Connell, D. \& Chu, C. 2017. Dermal Exposure of Applicators to Chlorpyrifos on Rice Farms in Ghana. Chemosphere, 178, 350-358.

Bassil, K. L., Vakil, C., Sanborn, M., Cole, D. C., Kaur, J. S. \& Kerr, K. J. 2007. Cancer Health Effects of Pesticides: Systematic Review. Can. Fam. Physician, 53, 1704-1711.

Behroozy, A. 2013. On Dermal Exposure Assessment. International Journal of Occupational and Environmental Medicine, 4, 113-27.

Botwe, B. O., Ntow, W. J. \& Nyarko, E. 2012. Pesticide Contamination in Groundwater and Streams Draining Vegetable Plantations in the Ofinso District, Ghana. In: Soriano, M. C. H. (ed.) Soil Health and Land Use Management. InTech.

Bradman, A., Salvatore, A. L., Boeniger, M., Castorina, R., Snyder, J., Barr, D. B., Jewell, N. P., Kavanagh-Baird, G., Striley, C. \& Eskenazi, B. 2009. Community-Based Intervention to Reduce Pesticide Exposure to Farmworkers and Potential Take-Home Exposure to Their Families. J. Expo. Sci. Environ. Epidemiol., 19, 79-89.

Cao, L., Chen, B., Zheng, L., Wang, D., Liu, F. \& Huang, Q. 2015. Assessment of Potential Dermal and Inhalation Exposure of Workers to the Insecticide Imidacloprid Using Whole-Body Dosimetry in China. J. Environ. Sci. (China), 27, 139-46. 
Cao, Q., Yu, Q. \& Connell, D. W. 2010. Fate Simulation and Risk Assessment of Endocrine Disrupting Chemicals in a Reservoir Receiving Recycled Wastewater. Sci. Total Environ., 408, 6243-50.

Chester, G. 1993. Evaluation of Agricultural Worker Exposure to, and Absorption of, Pesticides. Ann. Occup. Hyg., 37, 509-23.

Colombo, A., Orsi, F. \& Bonfanti, P. 2005. Exposure to the Organophosphorus Pesticide Chlorpyrifos Inhibits Acetylcholinesterase Activity and Affects Muscular Integrity in Xenopus Laevis Larvae. Chemosphere, 61, 1665-71.

Connell, D. 2005. Basic Concepts of Environmental Chemistry, Boca Raton FL., CRC Press Taylor and Francis Group.

Costa, L. G. 2006. Current Issues in Organophosphate Toxicology. Clin. Chim. Acta, 366, 113.

Damalas, C. A. \& Eleftherohorinos, I. G. 2011. Pesticide Exposure, Safety Issues, and Risk Assessment Indicators. Int. J. Environ. Res. Public Health, 8, 1402-19.

Darko, G. \& Akoto, O. 2008. Dietary Intake of Organophosphorus Pesticide Residues through Vegetables from Kumasi, Ghana. Food Chem. Toxicol., 46, 3703-6.

DFS - Department of Food Safety 2006. Analytical Methods for Residual Compositional Substances of Agricultural Chemicals, Feed Additives, and Veterinary Drugs in Food. Japan: Department of Food Safety, Ministry of Health, Labour and Welfare.

Dhillon, A. S., Tarbutton, G. L., Levin, J. L., Plotkin, G. M., Lowry, L. K., Nalbone, J. T. \& Shepherd, S. 2008. Pesticide/Environmental Exposures and Parkinson's Disease in East Texas. Journal of agromedicine, 13, 37-48.

Dowling, K. C. \& Seiber, J. N. 2002. Importance of Respiratory Exposure to Pesticides among Agricultural Populations. Int. J. Toxicol., 21, 371-81.

Durham, W. F. \& Wolfe, H. R. 1962. Measurement of the Exposure of Workers to Pesticides. Bull. World Health Organ., 26, 75-91.

Eaton, D. L., Daroff, R. B., Autrup, H., Bridges, J., Buffler, P., Costa, L. G., Coyle, J., Mckhann, G., Mobley, W. C., Nadel, L., Neubert, D., Schulte-Hermann, R. \& Spencer, P. S. 2008. Review of the Toxicology of Chlorpyrifos with an Emphasis on Human Exposure and Neurodevelopment. Crit. Rev. Toxicol., 38 Suppl 2, 1-125.

Edokpolo, B., Yu, Q. J. \& Connell, D. 2015. Health Risk Assessment for Exposure to Benzene in Petroleum Refinery Environments. Int. J. Environ. Res. Public Health, 12, 595-610. 
EPAG - Environmental Protection Agency of Ghana 2016. Pesticides Registration in Ghana. 252nd American Chemical Society National Meeting and Exposition. Philadelphia, Pennsylvania: American Chemical Society.

Farahat, F. M., Fenske, R. A., Olson, J. R., Galvin, K., Bonner, M. R., Rohlman, D. S., Farahat, T. M., Lein, P. J. \& Anger, W. K. 2010. Chlorpyrifos Exposures in Egyptian Cotton Field Workers. Neurotoxicology, 31, 297-304.

Fenske, R. A. 1993. Dermal Exposure Assessment Techniques. Ann. Occup. Hyg., 37, 687706.

Fenske, R. A., Farahat, F. M., Galvin, K., Fenske, E. K. \& Olson, J. R. 2012. Contributions of Inhalation and Dermal Exposure to Chlorpyrifos Dose in Egyptian Cotton Field Workers. Int. J. Occup. Environ. Health, 18, 198-209.

Fosu-Mensah, B. Y., Okoffo, E. D., Darko, G. \& Gordon, C. 2016. Organophosphorus Pesticide Residues in Soils and Drinking Water Sources from Cocoa Producing Areas in Ghana. Environmental Systems Research, 5, 10.

Frenich, A. G., Aguilera, P. A., Gonzalez, F. E., Castro Cano, M. L., Martinez Galera, M., Martinez Vidal, J. L. \& Soler, M. 2002. Dermal Exposure to Pesticides in Greenhouses Workers: Discrimination and Selection of Variables for the Design of Monitoring Programs. Environ. Monit. Assess., 80, 51-63.

Furlong, M., Tanner, C. M., Goldman, S. M., Bhudhikanok, G. S., Blair, A., Chade, A., Comyns, K., Hoppin, J. A., Kasten, M., Korell, M., Langston, J. W., Marras, C., Meng, C., Richards, M., Ross, G. W., Umbach, D. M., Sandler, D. P. \& Kamel, F. 2015. Protective Glove Use and Hygiene Habits Modify the Associations of Specific Pesticides with Parkinson's Disease. Environ. Int., 0, 144-150.

Geer, L. A., Cardello, N., Dellarco, M. J., Leighton, T. J., Zendzian, R. P., Roberts, J. D. \& Buckley, T. J. 2004. Comparative Analysis of Passive Dosimetry and Biomonitoring for Assessing Chlorpyrifos Exposure in Pesticide Workers. Ann. Occup. Hyg., 48, 68395.

Griffin, P., Mason, H., Heywood, K. \& Cocker, J. 1999. Oral and Dermal Absorption of Chlorpyrifos: A Human Volunteer Study. Occup. Environ. Med., 56, 10-3.

Grube, A., Donaldson, D., Kiely, T. \& Wu, L. 2011. Pesticides Industry Sales and Usage. US EPA, Washington, DC.

Health Canada 2014. Re-Evaluation Decision for Propoxur. Ottawa, Ontario: Health Canada Pest Management Regulatory Agency. 
Jamal, G. A., Hansen, S. \& Julu, P. O. 2002. Low Level Exposures to Organophosphorus Esters May Cause Neurotoxicity. Toxicology, 181-182, 23-33.

John, E. M. \& Shaike, J. M. 2015. Chlorpyrifos: Pollution and Remediation. Environ. Chem. Lett., 13, 269-291.

Koureas, M., Tsakalof, A., Tzatzarakis, M., Vakonaki, E., Tsatsakis, A. \& Hadjichristodoulou, C. 2014. Biomonitoring of Organophosphate Exposure of Pesticide Sprayers and Comparison of Exposure Levels with Other Population Groups in Thessaly (Greece). Occup. Environ. Med., 71, 126-33.

Lappharat, S., Siriwong, W., Taneepanichskul, N., Borjan, M., Maldonado Perez, H. \& Robson, M. 2014. Health Risk Assessment Related to Dermal Exposure of Chlorpyrifos: A Case Study of Rice Growing Farmers in Nakhon Nayok Province, Central Thailand. Journal of agromedicine, 19, 294-302.

Marasinghe, J., Yu, Q. \& Connell, D. 2014. Assessment of Health Risk in Human Populations Due to Chlorpyrifos. Toxics, 2, 92.

Mattah, M. M., Mattah, P. a. D. \& Futagbi, G. 2015. Pesticide Application among Farmers in the Catchment of Ashaiman Irrigation Scheme of Ghana: Health Implications. $J$. Environ. Public Health, 2015, 7.

Meuling, W. J., Ravensberg, L. C., Roza, L. \& Van Hemmen, J. J. 2005. Dermal Absorption of Chlorpyrifos in Human Volunteers. Int. Arch. Occup. Environ. Health, 78, 44-50.

Mueller, U., Bartholomaeus, A. \& Jenner, M. 2008. Dermal Absorption of Chemicals: Some Australian Regulatory Considerations. In: Roberts Michael, S. \& Walters, K. A. (eds.) Dermal Absorption and Toxicity Assessment. Taylor \& Francis

Munoz-Quezada, M. T., Lucero, B. A., Iglesias, V. P., Munoz, M. P., Cornejo, C. A., Achu, E., Baumert, B., Hanchey, A., Concha, C., Brito, A. M. \& Villalobos, M. 2016. Chronic Exposure to Organophosphate (Op) Pesticides and Neuropsychological Functioning in Farm Workers: A Review. Int. J. Occup. Environ. Health, 22, 68-79.

Ngo, M. A., O'malley, M. \& Maibach, H. I. 2010. Percutaneous Absorption and Exposure Assessment of Pesticides. J. Appl. Toxicol., 30, 91-114.

Nolan, R. J., Rick, D. L., Freshour, N. L. \& Saunders, J. H. 1984. Chlorpyrifos: Pharmacokinetics in Human Volunteers. Toxicol. Appl. Pharmacol., 73, 8-15.

Ntow, W. J., Drechsel, P., Botwe, B. O., Kelderman, P. \& Gijzen, H. J. 2008. The Impact of Agricultural Runoff on the Quality of Two Streams in Vegetable Farm Areas in Ghana. J. Environ. Qual., 37, 696-703. 
511

512

513

514

515

516

517

518

519

520

521

522

523

524

525

526

527

528

529

530

531

532

533

534

535

536

537

538

539

540

541

542

Ntow, W. J., Gijzen, H. J., Kelderman, P. \& Drechsel, P. 2006. Farmer Perceptions and Pesticide Use Practices in Vegetable Production in Ghana. Pest management science, $62,356-65$.

OECD 1997. Guidance Document for the Conduct of Studies of Occupational Exposure to Pesticides During Agricultural Application. OECD Environmental Health and Safety Publications, Series on Testing and Assessment.

Pan, U. M. \& Siriwong, W. 2010. Risk Assessment for Dermal Exposure of Organophosphate Pesticides in Rice-Growing Farmers at Rangsit Agricultural Area, Pathumthani Province, Central Thailand. Journal of Health Research, 24 (suppl 2), 141-148.

Phung, D. T., Connell, D. \& Chu, C. 2015. A New Method for Setting Guidelines to Protect Human Health from Agricultural Exposure by Using Chlorpyrifos as an Example. Ann. Agric. Environ. Med., 22, 275-80.

Phung, D. T., Connell, D., Miller, G. \& Chu, C. 2012. Probabilistic Assessment of Chlorpyrifos Exposure to Rice Farmers in Viet Nam. J. Expo. Sci. Environ. Epidemiol., 22, 417-23.

Pornpratansombat, P., Bauer, B. \& Boland, H. 2011. The Adoption of Organic Rice Farming in Northeastern Thailand. Journal of Organic Systems, 6.

Rauh, V. A., Perera, F. P., Horton, M. K., Whyatt, R. M., Bansal, R., Hao, X., Liu, J., Barr, D. B., Slotkin, T. A. \& Peterson, B. S. 2012. Brain Anomalies in Children Exposed Prenatally to a Common Organophosphate Pesticide. Proc. Natl. Acad. Sci. U. S. A., 109, 7871-7876.

Sadler, R., Maetam, B., Edokpolo, B., Connell, D., Yu, J., Stewart, D., Park, M. J., Gray, D. \& Laksono, B. 2016. Health Risk Assessment for Exposure to Nitrate in Drinking Water from Village Wells in Semarang, Indonesia. Environmental Pollution, 216, 738-45.

Schneider, T., Cherrie, J. W., Vermeulen, R. \& Kromhout, H. 2000. Dermal Exposure Assessment. The Annals of Occupational Hygiene, 44, 493-499.

Thongsinthusak, T. 1991. Determination of Dermal Absorption of Chlorpyrifos in Humans. In: Regulation, D. O. P. (ed.). Sacramento, California.

Thongsinthusak, T., Ross, J. H. \& Dong, M. H. 1999. Significance of Dermal Dose Levels in Dermal Absorption Studies of Pesticides. In: Regulation, C. D. O. P. (ed.). Sacramento, CA: California Environmental Protection Agency

Tsakirakis, A., Kasiotis, K. M., Arapaki, N., Charistou, A., Tsatsakis, A., Glass, C. R. \& Machera, K. 2011. Determination of Operator Exposure Levels to Insecticide During 
543

544

545

546

547

548

549

550

551

552

553

554

555

556

557

558

559

560

561

562

563

564

565

566

567

Bait Applications in Olive Trees: Study of Coverall Performance and Duration of Application. Int. J. Hyg. Environ. Health, 214, 71-78.

USEPA - United States Environmental Protection Agency 2007. Dermal Exposure Assessment: A Summary of Epa Approaches. Washington, DC: United States Environmental Protection Agency.

USEPA 1992. Guidelines for Exposure Assessment. Washington D.C.: U.S. Environmental Protection Agency, Risk Assessment Forum.

WHO - World Health Organization 1982. Field Surveys of Exposure to Pesticides Standard Protocol. Geneva: World Health Organization.

WHO - World Health Organization 2010. The Who Recommended Classification of Pesticides by Hazard and Guidelines to Classification 2009. Geneva: World Health Organization.

Whyatt, R. M., Rauh, V., Barr, D. B., Camann, D. E., Andrews, H. F., Garfinkel, R., Hoepner, L. A., Diaz, D., Dietrich, J., Reyes, A., Tang, D., Kinney, P. L. \& Perera, F. P. 2004. Prenatal Insecticide Exposures and Birth Weight and Length among an Urban Minority Cohort. Environ. Health Perspect., 112, 1125-32.

Wu, R. S., Chan, A. K., Richardson, B. J., Au, D. W., Fang, J. K., Lam, P. K. \& Giesy, J. P. 2008. Measuring and Monitoring Persistent Organic Pollutants in the Context of Risk Assessment. Mar. Pollut. Bull., 57, 236-44.

Yan, D., Zhang, Y., Liu, L. \& Yan, H. 2016. Pesticide Exposure and Risk of Alzheimer's Disease: A Systematic Review and Meta-Analysis. Sci. Rep., 6, 32222.

Yang, C. C. \& Deng, J. F. 2007. Intermediate Syndrome Following Organophosphate Insecticide Poisoning. J. Chin. Med. Assoc., 70, 467-72.

Zendzian, R. P. 1994. Dermal Absorption of Pesticides. . In: Programs, O. O. P. (ed.). Washington, DC.: United States Environmental Protection Agency. 


\section{List of Figure Captions}

Figure 1: Cumulative Probability Distribution (CPD) Plot of $\mathrm{ADD}_{\mathrm{D}}$ Levels of Chlorpyrifos from Dermal Exposure with Applicators on Rice Farms in Ghana.

Figure 2: Cumulative Probability Distribution Plot (CPD) of $\mathrm{LADD}_{\mathrm{D}}$ Levels of Chlorpyrifos from Dermal Exposure with Applicators on Rice Farms in Ghana. 
Figure 1

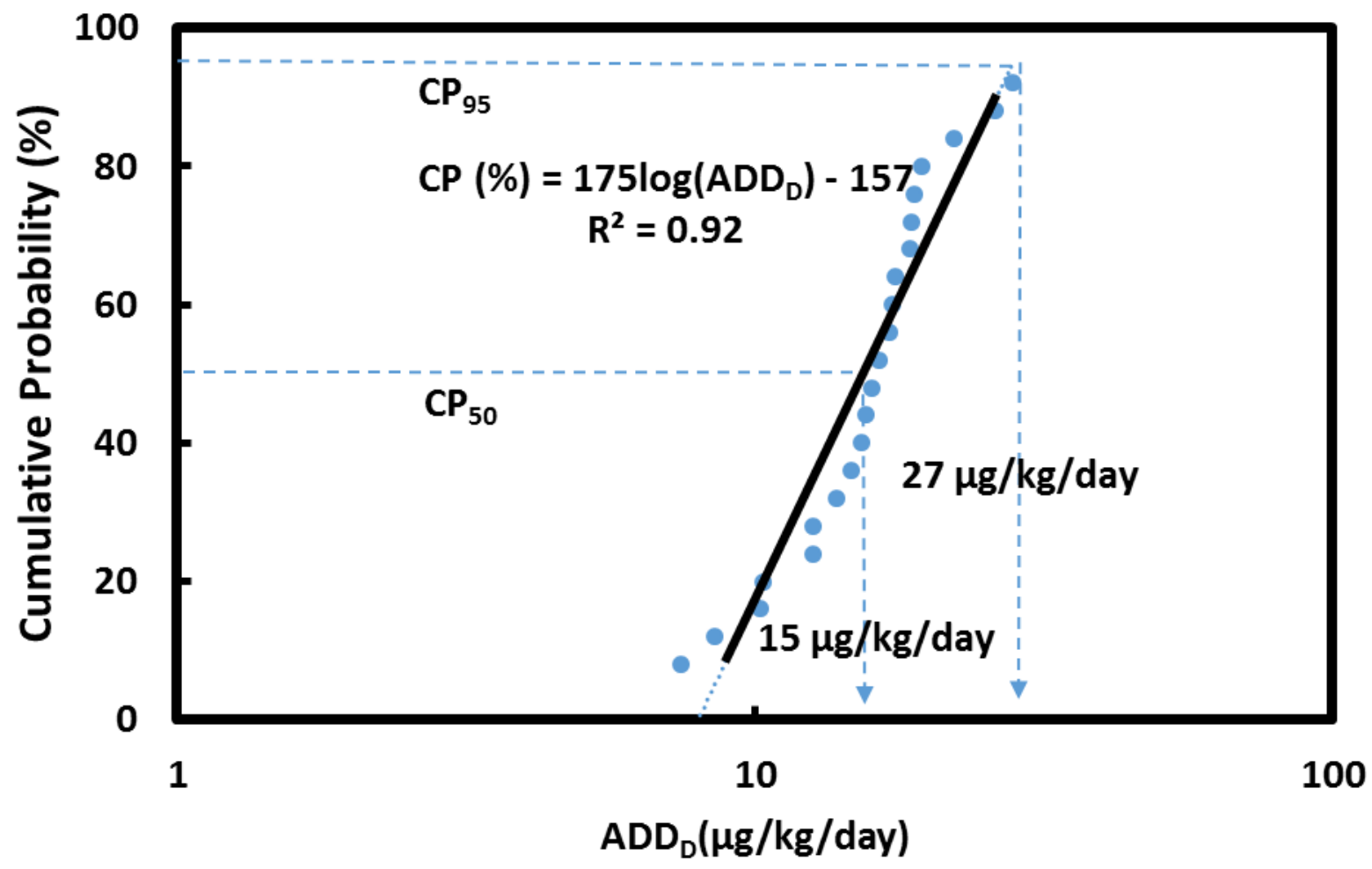


Figure 1

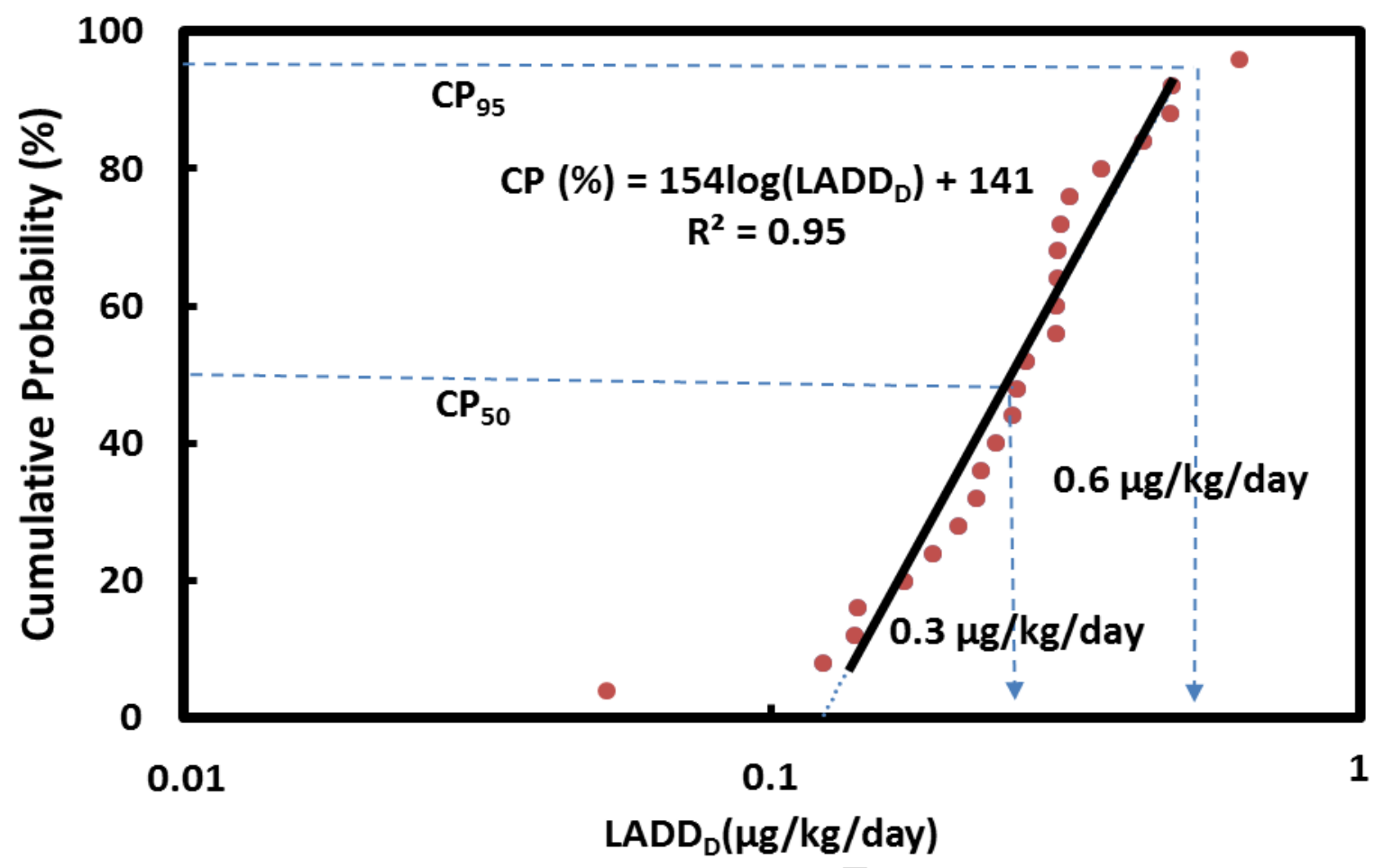




\section{HIGHLIGHTS}

- Absorbed dose levels of chlorpyrifos and health risk from dermal exposure were assessed.

- Acute dose among the median-exposed and 5\%-highly exposed groups were 15 and 27 $\mu \mathrm{g} / \mathrm{kg} / \mathrm{day}$, respectively.

- Chronic dose among the median-exposed and 5\%-highly exposed groups were 0.3 and $0.6 \mu \mathrm{g} / \mathrm{kg} /$ day, respectively.

- There was risk of acute health effects among both the median-exposed and 5\%-highly exposed groups.

- There was risk of chronic health effects among the 5\%-highly exposed group. 


\section{TABLES}

Table 1: Summary of Studies on Dermal Absorption Factor for Chlorpyrifos in Humans

\begin{tabular}{|c|c|c|c|}
\hline $\begin{array}{c}\text { Study } \\
\text { Parameter }\end{array}$ & $\begin{array}{c}\text { Nolan et al. } \\
(1984)\end{array}$ & $\begin{array}{c}\text { Griffin et al. } \\
\text { (1999) }\end{array}$ & $\begin{array}{c}\text { Meuling et al. } \\
(2005)\end{array}$ \\
\hline Number of study subjects & 6 & 5 & 3 \\
\hline Anatomical site & $\begin{array}{l}\text { Volar surface of the } \\
\text { forearm }\end{array}$ & $\begin{array}{l}\text { Volar surface of } \\
\text { the forearm }\end{array}$ & $\begin{array}{l}\text { Volar surface } \\
\text { of the forearm }\end{array}$ \\
\hline $\begin{array}{l}\text { Applied dose/quantity } \\
\text { ( } \mu \mathrm{g} / \mathrm{cm}^{2} \text { of skin) }\end{array}$ & 4,160 & 367 & 50 \\
\hline Exposure duration(hours) & 12 to 20 & 8 & 4 \\
\hline $\begin{array}{l}\text { Percentage of applied } \\
\text { dose/quantity washed off } \\
\text { after exposure duration }\end{array}$ & Not determined & & 42 \\
\hline Solvent/vehicle & $\begin{array}{l}\text { Dipropylene glycol } \\
\text { methyl ether or } \\
\text { methylene chloride }\end{array}$ & Water & Ethanol \\
\hline Sampling media & Urine & Urine and blood & Urine \\
\hline Sampling period (hours) & $120+$ & 100 & 120 \\
\hline Metabolite analysed & TCP & TCP & TCP \\
\hline $\begin{array}{c}\text { Dermal Absorption } \\
\text { Factor }(\%)\end{array}$ & 1.28 & 1 & 4.3 \\
\hline
\end{tabular}


Table 2: Total Dermal Exposure (TDE), Absorbed Daily Dose $\left(\mathrm{ADD}_{\mathrm{D}}\right)$ and Lifetime Average Daily Dose $\left(\mathrm{LADD}_{\mathrm{D}}\right)$ of Chlorpyrifos from Dermal Exposure with the Applicators $(n=24)$

\begin{tabular}{|c|c|c|c|}
\hline Parameter & $\begin{array}{c}\text { TDE } \\
(\mu \mathrm{g} / \mathbf{d a y})\end{array}$ & $\begin{array}{c}\mathbf{A D D}_{\mathbf{D}} \\
(\boldsymbol{\mu g} / \mathbf{k g} / \mathbf{d a y})\end{array}$ & $\begin{array}{c}\mathbf{L A D D} \\
(\boldsymbol{\mu} \mathbf{g} / \mathbf{k g} / \mathbf{d a y})\end{array}$ \\
\hline Minimum & 9,700 & 5 & 0.1 \\
\hline Mean $( \pm \mathrm{SD})$ & $25,800( \pm 9,900)$ & $16( \pm 6)$ & $0.3( \pm 0.1)$ \\
\hline Maximum & 48,900 & 29 & 0.5 \\
\hline
\end{tabular}


Table 3: Hazard Quotients $\left(\mathrm{HQ}_{50}\right.$ and $\left.\mathrm{HQ}_{95}\right)$ for $\mathrm{ADD}_{\mathrm{D}}$ Levels of Chlorpyrifos from Dermal Exposure with Applicators on Rice Farms in Ghana $(n=24)$

\begin{tabular}{|l|c|c|c|c|c|}
\hline \multicolumn{2}{|c|}{ Guideline } & \multicolumn{2}{c|}{ ADD $_{\mathbf{D}}(\boldsymbol{\mu g} / \mathbf{k g} /$ day $)$} & \multicolumn{2}{c|}{ Hazard Quotient } \\
\hline \multicolumn{1}{|c|}{ Reference } & Value( $\boldsymbol{\mu g} / \mathbf{k g} /$ day) & CP $_{\mathbf{5 0}}$ & $\mathbf{C P}_{\mathbf{9 5}}$ & HQ $_{\mathbf{5 0}}$ & HQ $_{\mathbf{9 5}}$ \\
\hline WHO (2009) & 100 & 15 & 27 & 0.2 & 0.3 \\
USEPA (2000) & 5 & 15 & 27 & $\mathbf{3 . 0}$ & $\mathbf{5 . 4}$ \\
APVMA (2009) & 10 & 15 & 27 & $\mathbf{1 . 5}$ & $\mathbf{2 . 7}$ \\
Phung et al (2015) & 3 & 15 & 27 & $\mathbf{5 . 0}$ & $\mathbf{9 . 0}$ \\
\hline
\end{tabular}

(HQ values $>1$ are in bold) 
Table 4: Hazard Quotients $\left(\mathrm{HQ}_{50}\right.$ and $\left.\mathrm{HQ}_{95}\right)$ for $\mathrm{LADD}_{\mathrm{D}}$ Levels of Chlorpyrifos from Dermal Exposure with Applicators on Rice Farms in Ghana $(\mathrm{n}=24)$

\begin{tabular}{|l|c|c|c|c|c|}
\hline \multicolumn{2}{|c|}{ Guideline } & \multicolumn{2}{c|}{ LADD $_{\mathbf{D}}(\boldsymbol{\mu g} / \mathbf{k g} /$ day $)$} & \multicolumn{2}{c|}{ Hazard Quotient } \\
\hline \multicolumn{1}{|c|}{ Reference } & Value( $\boldsymbol{\mu g} / \mathbf{k g} / \mathbf{d a y})$ & $\mathbf{C P}_{\mathbf{5 0}}$ & $\mathbf{C P}_{\mathbf{9 5}}$ & HQ $_{\mathbf{5 0}}$ & HQ $_{\mathbf{9 5}}$ \\
\hline WHO (2009) & 10.0 & 0.3 & 0.6 & 0.03 & 0.1 \\
USEPA (2000) & 0.3 & 0.3 & 0.6 & 1.0 & $\mathbf{2 . 0}$ \\
APVMA (2009) & 3.0 & 0.3 & 0.6 & 0.1 & 0.2 \\
Phung et al (2015) & 0.5 & 0.3 & 0.6 & 0.6 & $\mathbf{1 . 2}$ \\
\hline
\end{tabular}

(HQ values $>1$ are in bold) 


\section{Accepted Manuscript}

Health Risk Assessment of Dermal Exposure to Chlorpyrifos among Applicators on Rice Farms in Ghana

Albert Atabila, Dung Tri Phung, Jonathan N. Hogarh, Ross Sadler, Des Connell,

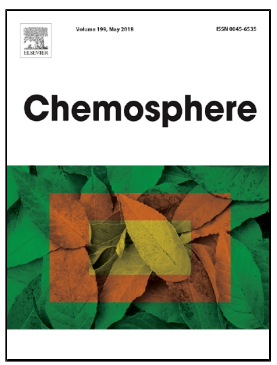
Cordia Chu

PII: S0045-6535(18)30538-1

DOI: 10.1016/j.chemosphere.2018.03.121

Reference: CHEM 21065

To appear in: Chemosphere

Received Date: 05 December 2017

Revised Date: 24 February 2018

Accepted Date: 18 March 2018

Please cite this article as: Albert Atabila, Dung Tri Phung, Jonathan N. Hogarh, Ross Sadler, Des Connell, Cordia Chu, Health Risk Assessment of Dermal Exposure to Chlorpyrifos among Applicators on Rice Farms in Ghana, Chemosphere (2018), doi: 10.1016/j.chemosphere. 2018.03.121

This is a PDF file of an unedited manuscript that has been accepted for publication. As a service to our customers we are providing this early version of the manuscript. The manuscript will undergo copyediting, typesetting, and review of the resulting proof before it is published in its final form. Please note that during the production process errors may be discovered which could affect the content, and all legal disclaimers that apply to the journal pertain. 